\title{
ENSINO DE LÍNGUAS E CULTURAS ESTRANGEIRAS EM TEMPOS DE (PÓS) PANDEMIA: DESAFIOS E APRENDIZAGENS DE EDUCADORES NA CHINA
}

\author{
Angela Teodoro Grillo* \\ Michaela Péskova** $^{* *}$
}

A crise sanitária da Covid-19 tem afetado segmentos econômicos e sociais em países de todo o planeta. A China, primeiro país a enfrentar a situação, mostrou que o respeito às medidas de isolamento social serve como meio eficiente para a diminuir a contaminação do corona vírus, conduta também recomendada pela Organização Mundial de Saúde. No campo educacional, as escolas e universidades chinesas cumpriram de forma urgente a demanda da continuidade do ensino por via remota, evitando a paralisação ou atraso no período letivo; no mês de maio de 2020 , diante do controle efetivo da crise sanitária, a volta às aulas presenciais foi regularizada em diferentes províncias chinesas.

Nesta entrevista, realizada no mês de agosto, convidamos seis professores que ensinam em universidades da província de Zhejiang, de diferentes nacionalidades e continentes, que se encontram em situações de ensino remoto ou presencial, para refletirem sobre como têm vivenciado o trabalho educacional no presente contexto e como pensam a educação no pós-pandemia. Assim como em sistemas educacionais de outras partes do mundo, todos os entrevistados enfrentaram ou ainda enfrentam uma nova realidade imposta pela crise sanitária que exige novas estratégias de ensino e aprendizagem que advêm tanto do maior uso de tecnologias, como da própria necessidade de repensar o papel do educador.

A entrevista a seguir foi realizada individualmente por e-mail com cada um de nossos convidados, e as respostas obtidas, reunidas posteriormente com vistas a ressaltar o caráter polifônico que o debate sobre ensino e pandemia implica. Os professores responderam em suas línguas maternas - portuguesa, inglesa e chinesa - a presente edição em versão completa em língua portuguesa conta com trabalho de tradução sob responsabilidade da professora Jackeline Lee ${ }^{* * *}$ do Departamento de Português da Zhejiang Yuexiu University of Foreign Languages.

Com o desejo de contribuir para a ampliação dos diálogos educacionais, internacionais e humanitários, agradecemos a participação dos nossos convidados, da tradutora e dos editores da presente revista.

\footnotetext{
*Angela Teodoro Grillo é brasileira, doutora em Letras pelo Programa de Literatura Brasileira da FFLCHUSP, pós-doutoranda em Cultura e identidades brasileiras pelo IEB/USP e professora do Departamento de Português da Zhejiang Yuexiu University of Foreign Languages.

** Michaela Péskova é tcheca, graduada em Sociologia, mestre em Literatura e Sociologia pela Masaryk University, Brnoe e professora do Departamento de Tcheco da Zhejiang Yuexiu University of Foreign Languages

*** Jackeline Lee é brasileira, graduada em Ciências Econômicas pela UNESP, mestre em Ensino de Língua Chinesa para Estrangeiros pela Universidade de Hubei e atualmente é professora estrangeira no Departamento de Português da Universidade Zhejiang Yuexiu de Línguas Estrangeiras.
} 
1- Como sabemos, a contaminação pelo Corona vírus iniciou-se em janeiro deste ano, no final do período de férias escolares, quais foram os primeiros impactos da pandemia para a continuidade do seu trabalho como professor?

José Medeiros - Penso que pelo fato de estarmos em plenas férias de inverno, esse foi um fator atenuante. Como não estávamos no meio das aulas, não tivemos que interromper apressadamente os trabalhos e, com isso, ganhamos um precioso tempo para, de quarentena, acompanharmos melhor o desdobramento da situação. Evidentemente que, em um primeiro momento, as incertezas em relação ao controle da pandemia impactaram profundamente, pois não sabíamos qual o verdadeiro desdobramento da situação. Felizmente, com o esforço do governo e a colaboração do povo, a situação passou a ser bem administrada e o novo semestre, mesmo que virtualmente, pode ser iniciado. Claro que, como professor, grande foi o esforço para nos adaptar a uma rotina de trabalho completamente nova e desafiadora.

Song Yuenan - No início, eu fiquei sabendo do covid-19 por meio dos noticiários. Além disso, não houve casos confirmados de covid-19 na área onde que resido, por isso não foi dada muita atenção, mas como estávamos prestes a entrar de férias os colegas foram alertados para que não planejassem viagens para locais com casos confirmados.

Amit Sharma - No início, eu não levei o covid-19 a sério e assumi que fosse um vírus normal. Eu achei que desapareceria depois de um tempo, assim que o clima mudasse do frio para o calor! E esse semestre possivelmente começaria semanas depois do programado.

André Veloso - O início do segundo semestre foi adiado e o retomo das aulas foi feito por via remota. A situação manteve-se durante alguns meses até à escola voltar a ter aulas presenciais, que tinham de seguir as regras de distanciamento social.

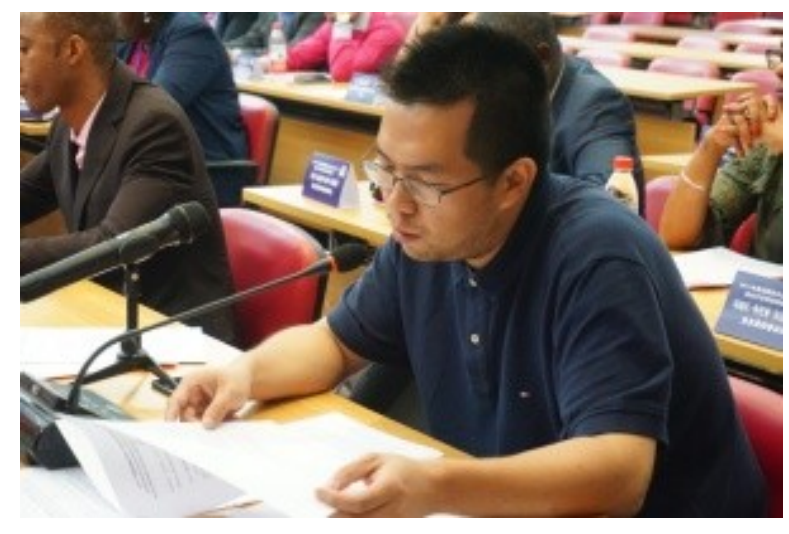

JINGXIN XU, (DIEGO) nasceu em Hangzhou, China. É Licenciado em

Tradução ChinêsPortuguês pelo Instituto Politécnico de Macau, Mestre em Tradução pela Universidade de Macau, atua como coordenador do Departamento de Português da Universidade de Línguas Estrangeiras de Zhejiang Yuexiu, pesquisador especializado na literatura brasileira, tradutor de obras de Lima

Barreto, Alvarez de Azevedo e Simões Lopes Neto. Autor do Dicionário de Regência de Língua Portuguesa (2020) para chineses. 
2- Em comparação ao sistema educacional de seu país, como considerou a adaptação da universidade e dos alunos chineses às aulas remotas?

José Medeiros - Por já estar a muitos anos vivendo e trabalhando na China, não tenho uma noção exata de como o sistema educacional brasileiro reagiu a essa situação. Pelas conversas informais mantidas com familiares e amigos, parece-me que a China conseguiu ser mais eficiente nas respostas a esse novo desafio, especialmente no uso de novas tecnologias de comunicação e na capacidade de mobilizar e sincronizar esforços, tanto das instituições quanto das pessoas - administradores, professores, famílias, estudantes. No caso específico dos nossos alunos, a consciência deles sobre a importância da educação para suas vidas foi, sem dúvida, um fator decisivo para que melhor se adaptassem a essas novas circunstâncias.

Song Yuenan - O pico do covid-19 coincidiu com a data programada para $o$ início do semestre, nesse momento, o Ministério da Educação e a direção da universidade estavam cientes o retorno das aulas traria perigo aos professores e alunos, por isso foi repassado aos departamentos que eles deveriam começar os preparativos das aulas online, bem como oferecer treinamento das aulas online para que os professores conseguissem se adaptar, caso surgisse algum problema.

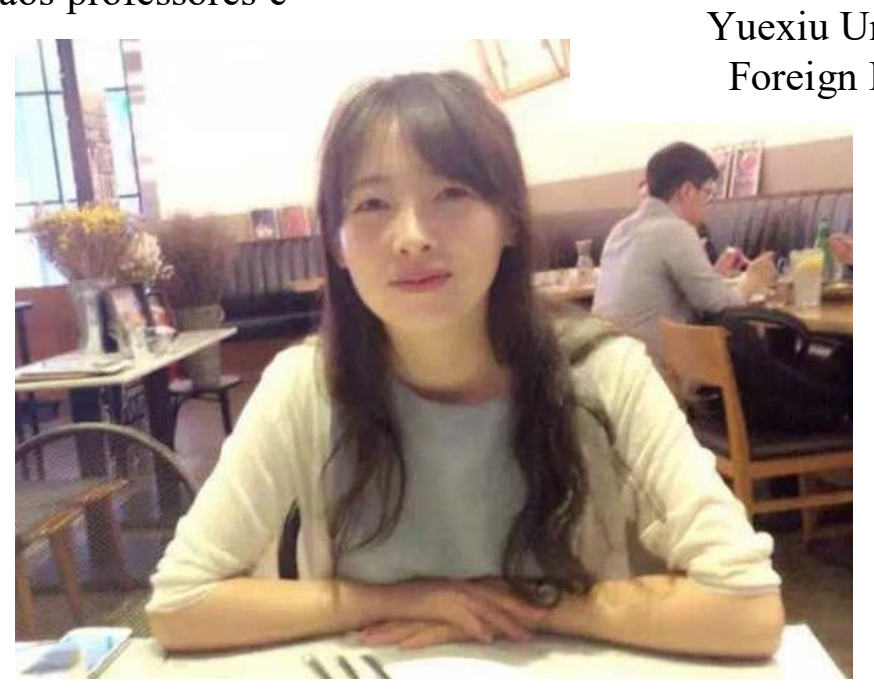

Atualmente, o sistema de informação do nosso país é desenvolvido, todos os alunos têm condições para assistir a aulas online, por isso elas conseguiram ser concretizadas de forma rápida.

Amit Sharma - Em geral a China, os chineses, os nossos alunos e o nosso sistema universitário (ZYUFL) são de longe mais flexíveis, inovadores e adaptáveis que a Índia. A Faculdade de Negócios Internacionais (COIB) não só adaptou às mudanças advindas do covid (início das aulas postergado, número de salas de aulas limitadas, professores não autorizados a voltar, etc), mas também adotou e integrou $\mathrm{o}$ ensino $\mathrm{e}$ aprendizado online com softwares como o DINGTALK no sistema pedagógico rapidamente. Os professores, estudantes, funcionários e administradores trabalharam juntos e não tiveram problemas para alcançar excelentes resultados.

SONG YUENAN nascida em Benxi, China. É licenciada em Língua Coreana e Mestre pela Universidade Kyung Hee, na Coréia do Sul (2016).

Leciona desde a graduação e atualmente é professora do Departamento de Coreano na Zhejiang Yuexiu University of Foreign Languages.

nosso pais é desenvolvido, todos os 
JingxinXu - No começo, os alunos não achavam que as aulas online eram muito animadas, porque não conseguiam ver a reação dos professores, mas por outro lado, talvez os alunos também gostassem das aulas online, porque não precisavam acordar tão cedo, dado que só precisam ligar o computador para assistir as aulas. De forma geral, depois da segunda, terceira semana de aulas, a maioria dos alunos já tinha conseguido se adaptar bem. No entanto, depois do primeiro e segundo mês, os colegas já sentiam cansados das aulas online.

Lavota Carter - Foi difícil adaptar da sala de aula interativa para o sistema online. $\mathrm{O}$ atraso no streaming, a falta de foco, juntamente com uma quantidade maior de aulas principalmente focadas na palestra do professor foram todos fatores que não permitiram que fosse mantida a atmosfera das aulas no período pré pandemia.

André Veloso - Uma vez que a maioria dos alunos tem acesso a Internet de alta velocidade e a equipamento eletrônico adequado para assistir às aulas online não houve muita dificuldade na adaptação por parte dos alunos. Pela minha parte, foi um pouco difícil me ajustar numa fase inicial à falta de feedback que recebia durante as aulas, onde a interação foi reduzida para quase zero, talvez em Portugal este aspeto tenha apresentado outro tipo de desafios devido à natureza mais interativa das aulas.

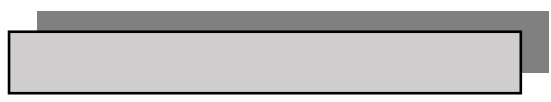

3- Quais foram as dificuldades encontradas? Quais foram as aprendizagens que você considera que lhe servirão para o seu trabalho no pós-pandemia? (considere a situação em que se encontra, se voltou à sala de aula ou ainda está trabalhando de forma remota).

José Medeiros - Inicialmente, as maiores dificuldades estavam ligadas ao uso das tecnologias e à adoção de uma metodologia de ensino mais apropriada para essas aulas remotas. Porém, especialmente devido o empenho dos alunos, pouco a pouco, conseguimos superar muitas dessas dificuldades iniciais. Por exemplo, verificamos que o estudo do material audiovisual seria muito mais eficiente se fosse compartilhado com antecedência, pois apesar do avanço das tecnologias, os ruídos técnicos ainda são muito comuns nesse tipo de transmissão. Outro aspeto diz respeito à interação face a face, bem diferente da aula presencial. Pessoalmente, o maior aprendizado foi observar que quando temos propósitos bem definidos poderemos obter grandes êxitos, por mais que a situação seja adversa. Acho que foi esse o caso dos nossos alunos e da nossa universidade. Mesmo diante de uma situação muito difícil nossa instituição conseguiu encontrar um caminho satisfatório para que assim o processo de ensinoaprendizagem não fosse interrompido. Curiosamente, no semestre passado (março-julho de 2020), dois terços das nossas aulas foram remotas e um terço presencial.

Song Yuenan - Eu tive alguns problemas técnicos com as aulas online, mas os profissionais responsáveis das aulas online me ajudaram rapidamente a resolvê-los. Como as aulas não eram interativas, talvez o maior problema que eu tive foi a dificuldade de saber se os 
alunos assimilavam completamente as aulas, por isso a universidade nos encorajou a melhorar o conteúdo das aulas para que os alunos conseguissem se concentrar melhor. Depois de passar por essa experiência pela primeira vez, passei a utilizar mais recursos da internet e consegui criar a capacidade de mudar da aula interativa e online a qualquer momento.

Amit Sharm - Foi difícil preparar os exaustivos recursos de ensino como as apresentações em Power Point, perguntas e testes para gerar discussões na aula online. No início, foi difícil engajar os alunos e avaliar a qualidade da participação dos alunos nas aulas. A boa conectividade da internet é uma necessidade nas aulas online. Eu acho que o covid-19 me deu a oportunidade de desenvolver aulas online utilizando áudio e vídeos, bem como conseguir utilizar este modelo de aprendizado combinado com as aulas interativas também (pós covid-19). Eu estou contente por ter aprendido esta nova habilidade.

JingxinXu - Na verdade, o principal problema diz respeito às disciplinas que nós ministramos. Se fossem aulas de administração, economia, comércio internacional, o professor poderia dar a aula baseada na apresentação Power Point e provavelmente não teria muita diferença nos resultados, embora seja difícil comprovar isso. Mas aprender línguas... Não dá para ver o professor estrangeiro. Pode-se comparar a aula online com a compra de uma aula prégravada online, ou assistir a um vídeo no youtube. Portanto, eu tenho dúvida de quanto tempo é possível ser pró ativo no estudo.

Lavota Carter - Como eu tinha mencionado antes, a principal dificuldade é a falta de foco dos alunos, dado que eles apenas podem sentar e assistir as aulas, por causa das restrições das plataformas utilizadas no aprendizado remoto. Lidar com a internet (e os seus problemas de conexão) em tempo real muitas vezes corta a o tempo designado para a aula pela metade.

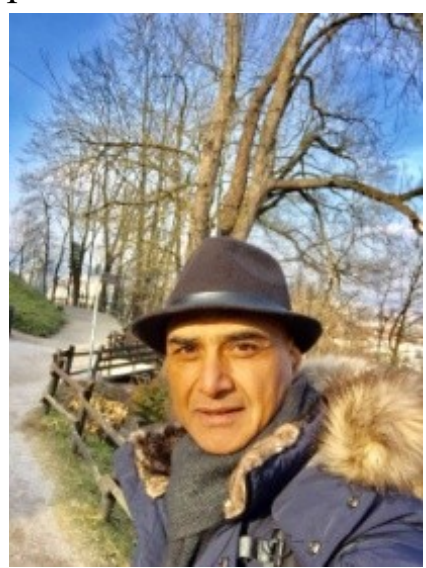

AMIT SHARMA nasceu em

Buland'hr, India. É doutor em Ciências Administrativas pela Universidade de Mysore, Índia; mestre em Economia pela Universidade Eastern Hill, Índia e bacharel em Economia pela Universidade de Delhi. Trabalhou como professor associado no Instituto de Administração e Tecnologia em Birla. Em 2016, mudou-se para China para ensinar Economia e Administração no College of International Business at ZYUFL, Shaoxing. Atualmente é vicereitor de internacionalização na mesma instituição onde é responsável pela área de ensino, pesquisa e colaborações internacionais. 
André Veloso - Houve um período inicial em que foi preciso aprender como usar o software utilizado nas aulas, e com o passar do tempo foi necessário adaptar a forma de lecionar, assim como os exercícios e outras tarefas. Aprender a utilizar este novo tipo de software e a adaptar a um novo tipo de realidade vão me permitir variar um pouco mais a maneira como ensino as aulas.

\section{Na sua opinião, um ensino por contato pode ser totalmente substituído pelo ensino remoto? Você acha que isso seja possível no ensino de idiomas? Em caso afirmativo, em quais disciplinas?}

José Medeiros - Penso que o mais profundo de uma formação universitária é o ambiente e convivência humana. Todos juntos, professores, alunos e administradores com um só propósito: ensinar e aprender. Nesse sentido, penso que o ensino presencial é insubstituível. Evidentemente que as novas tecnologias devem ser aproveitadas, mas apenas para que se dinamize ainda mais esse processo de interação e de aprendizagem. Quem sabe palestras, seminários e até mesmo, ocasionalmente, uma ou outra disciplina específica, como por exemplo, História, etc. Mas tudo tendo por base de interação um cotidiano acadêmico presencial.

Song Yuenan. - Dar as aulas online é muito conveniente e flexível no que tange às horas e o local onde se podem assistir as aulas, também é possível utilizar alguns recursos da internet no conteúdo da aula, mas eu não acredito que o ensino remoto consiga substituir totalmente o ensino por contato.
JingxinXu - Como mencionado na resposta da pergunta acima, não é totalmente substituível. Eu acredito que os alunos que tiveram o ensino remoto provavelmente diminuíram o seu nível de português ao do primeiro ano. Ao aprender uma língua, é possível estudar sozinho a escrita e leitura, mas o ensino remoto não consegue resolver a dificuldade do aprendizado do oral e audição.

Lavota Carter - Eu não acredito que o ensino por contato consiga ser substituído pelo remoto. Eu acredito que haja possibilidade do ensino remoto ser um meio utilizado para a educação, mas somente se ambos os lados da equação tiverem o mesmo material, acesso e assumam as devidas responsabilidades. Contudo, o ensino remoto não consegue substituir toda a experiência em volta do ensino por contato.

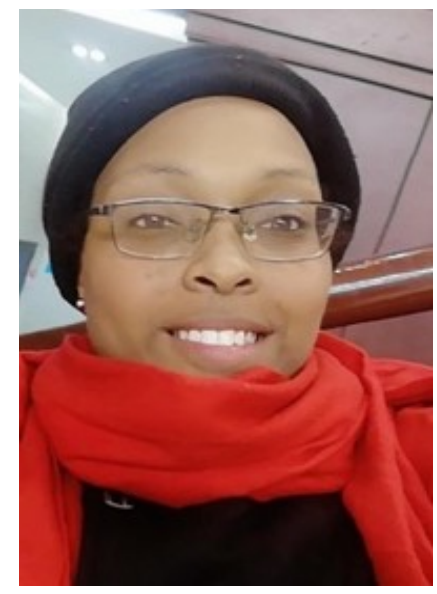

LAVOTA CARTER, nasceu na Pennsylvania, USA, é graduada em Antropologia (B.A.) e Ciências Biológicas (B.S.), pela Universidade de Pittsburgh. Mestre em Arte de Estudos Internacionais pela Concordia University Irvine. Possui certificado TOESFL e atua como professora no Departamento de Inglês da Zhejiang Yuexiu University of Foreign Languages. 
André Veloso. Em certos casos acredito que seja possível, mas depende, sobretudo do tipo de aluno. Alguns conseguem se adaptar bem e têm autodisciplina suficiente para conseguir estudar em casa, outros devido a um ambiente familiar menos tranquilo ou outros fatores continuam a preferir $o$ ensino presencial.

\section{Qual é o papel de um professor no ensino remoto? Ao comparar o ensino por contato com o ensino remoto, quais diferenças percebe? Esse papel é culturalmente condicionado? Em caso afirmativo, em que sentido (dada a sua experiência de ensino na China ou em diferentes países)? De alguma forma, isso se reflete no ensino remoto?}

José Medeiros - O papel de um professor seja em uma sala de aula virtual ou presencial é praticamente o mesmo. Além de transmitir valores humanos elevados, que sirvam de inspiração para os alunos, o professor deve conquistar a confiança de seus alunos e motivá-los para que se esforcem e se envolvam cada vez mais com o processo de aprendizagem. E, obviamente, o professor deve ser capaz de, remota ou presencialmente, e transmitir o conjunto de conhecimento específico relacionado a cada disciplina. Sobre esses dois tipos de transmissão de conhecimento, o remoto e o presencial, um não pode ser visto como substituto do outro. Podem até mesmo se complementar, mas não substituir. No aspeto técnico da aprendizagem, claro que se poderá obter bons resultados com qualquer um desses processos. Mas como já falei anteriormente, universidade é sobretudo vivência. E vivência em um espaço que pela sua própria concepção pressupõe interação entre diversidade de cursos, disciplinas, conhecimentos... Viver a universidade é, sobretudo, dedicar-se alguns anos de vida para uma imersão intensa dentro de um espaço de testes e desafios constantes, onde diversos saberes e vivências se percebem, surgem, dialogam e seguem a transformar, para sempre, as vidas que por ali passaram. Nesse sentido, essa vivência, mesmo que culturalmente condicionada, ela é única.

JOSÉ MEDEIROS DA SILVA (施若杰),

Nasceu no Rio Grande do Norte, Brasil, é graduado em Letras pela Universidade Federal do Rio Grande do Norte (1992), mestre em Comunicação e Semiótica pela Pontifícia Universidade Católica de São Paulo (1996) e doutor em Ciência Política pela Universidade de São Paulo (2008), sobre aspectos políticos da questão camponesa na China. Em 2007, migrou para China para ensinar língua portuguesa na Universidade de Estudos Internacionais de Xi'an. Em 2010, recebeu do governo da província de Shaanxi o Prêmio da Amizade "Sanqin" (三秦友谊) e em agosto do mesmo ano passou a trabalhar no Instituto de Comunicação de Hebei, em Shijiazhuang. Em 2012, passou a trabalhar no

Departamento de Português da Rádio Internacional da China, em Beijing. Desde 2015, trabalha em Hangzhou na Universidade de Estudos Internacionais de Zhejiang (浙江外国语学院). Atualmente, além das atividades de ensino, desenvolve pesquisas sobre questões políticas e sociais do Brasil e da China. shiruojie@gmail.com

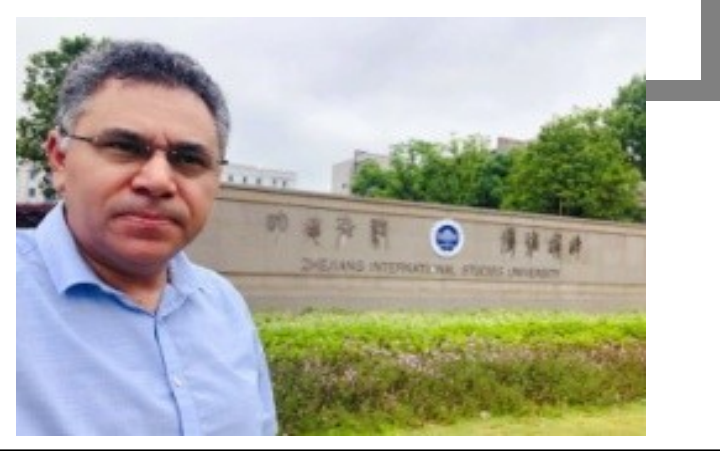


Song Yuenan - O professor no ensino remoto precisa ter a função de mentor e guia. No ensino por contato feito na sala de aula é mais fácil interagir e conseguir a atenção dos alunos, mas no remoto não é possível controlar o ambiente de aprendizado do aluno, assim como é mais difícil saber se alguém ou algo está afetando a concentração do aluno. Dessa forma, o nível de aprendizado do aluno no ensino remoto se torna menor que o do por contato.

Amit Sharma - No meu ponto de vista, o papel do professor no seu nível fundamental não muda independentemente do método. Mas, o ensino remoto exige uma maior preocupação na mentoria, orientação e promoção. $\mathrm{O}$ ensino remoto também exige um alto nível de conhecimento de tecnologia. A cultura é a parte inerente e inextricável do aprendizado e ensino. Tendo a experiência de ensinar em uma variedade de instituições e ter tido contato com estudantes de culturas diversas me fez descobrir que a linguística e a pluralidade cultural na sala de aula tem sido extremamente gratificante para mim. Esta variedade enriquece tanto $\mathrm{o}$ aluno como $\mathrm{o}$ professor no que tange o aprendizado e engajamento.

JingxinXu - Eu acredito que a diferença seria a inexistência de uma supervisão eficaz aos alunos, dado que o método de ensino de línguas na China para os alunos do primeiro e segundo ano ainda segue o método tradicional de treinamento, isto é, os alunos ouvem e o professor fala, o que deve ser memorizado e anotado. Com a chegada do ensino remoto, fica mais difícil supervisionar diariamente a memorização do aluno, ficando totalmente dependente da consciência do aluno e não posso ter certeza de quantos tem autodisciplina suficiente para realizar estas tarefas. A partir desse ponto de vista, eu acredito ainda mais que o papel do professor no ensino remoto é o de emissor de conhecimento. Antes na sala de aula ainda era possível ser um supervisor e agora este papel de supervisor se tornou bem enfraquecido. É como se fosse um canal de uma televisão, agora os alunos conseguem assistir vários canais, mas antes no dado tempo só conseguiam assistir uma disciplina na sala de aula.

Lavota Carter - O papel do professor no ensino remoto é fornecer uma estrutura aos alunos e, ao mesmo tempo, se esforçar para ser capaz de solucionar problemas ou orientar para esse esforço. Por fim, dependendo da plataforma utilizada, o professor pode precisar monitorar e avaliar, rotular $\mathrm{o}$ comportamento do aluno de uma forma mais rigorosa. Quando se compartilha o espaço físico é mais fácil chamar atenção e controlar o ambiente. $\mathrm{O}$ aprendizado remoto depende da dedicação de cada um dos indivíduos a aula que estão assistindo. As salas de aula virtuais são mais difíceis de serem monitoradas. Eu não tenho certeza se é devido a condicionantes culturais, mas o melhor método de ensino remoto nas situações online é a aula expositiva. A maioria dos professores estrangeiros que eu tive contato foi encorajada a terem aulas mais interativas, empolgantes e culturalmente informativas. As aulas expositivas sem o tempo adequado para permitir os alunos se expressarem, não favorecem este tipo de ambiente. 


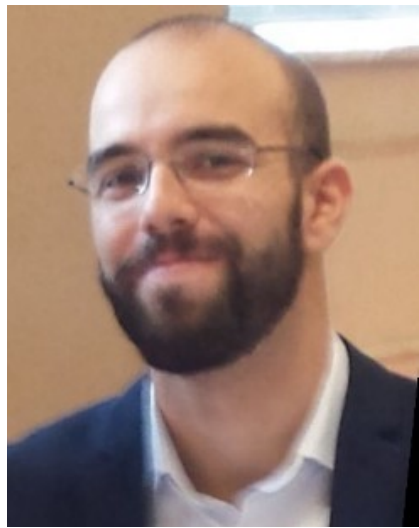

ANDRÉ VELOSO nasceu em Braga, Portugal, é graduado em Línguas e Culturas Orientais na Universidade do Minho.

Mestre em Estudos

Interculturais Português

/Chinês, com intercâmbio na

Universidade de Tianjin. Atuou como professor de mandarim em Portugal e professor de PLE na Universidade de Hebei por dois anos. Atualmente ensina no Departamento de Português da Universidade de ZheJiang Yuexiu

\section{Na sua opinião, quais podem ser os efeitos da pandemia na educação?}

André Veloso - Para mim acho que o papel fundamental do ensino foi ainda mais enfatizado, mesmo num período tão extraordinário como aquele que passamos, a educação é algo que dificilmente pode parar completamente ou ser substituído. Apesar de muitas indústrias terem sido extremamente afetadas pela pandemia, o ensino apesar de também ter sofrido, comparativamente foi num grau menor. Talvez a percepção de ser uma área com estabilidade e cujo emprego poderá sobreviver apesar de crises inesperadas possa atrair mais pessoas e melhorar a sua qualidade.
José Medeiros - Questões sobre o impacto das novas tecnologias no futuro do ensino e do próprio sistema educacional essa já estavam colocadas antes da crise do coronavírus e, claro, que agora essas discussões devem ser intensificadas e aprofundadas. No caso específico do ensino remoto durante a crise do coronavírus, vejo isso apenas como uma resposta pontual diante de uma situação extraordinária. Nesse sentido, todo o êxito alcançado deve ser ponderado considerando-se as próprias limitações e urgências impostas pelo referido contexto.

Vale salientar aqui que o sistema educacional atual é muito complexo e qualquer mudança apressada poderia ter um impacto irreversível e não necessariamente positivo. Por isso, acredito que nas próximas décadas o sistema vigente continuará se aperfeiçoando gradualmente, mas sem passar mudanças tão abruptas como, por exemplo, a substituição das aulas presenciais por aulas remotas.

Song Yuenan - Como na universidade há um contato maior entre as pessoas, a possibilidade de contágio acaba sendo maior por isso certamente terá uma profunda influência no ensino. Agora, o sistema que a universidade tem implementado é uma divisão controlada das aulas para diminuir a circulação dos alunos, assim como isolar o campus e aplicar uma política rigorosa de saída.

Amit Sharma - Eu acho que as universidades precisarão adotar um modelo de ensino combinado mais agressivo no futuro. $\mathrm{O}$ ensino baseado puramente no contato terá que se integrar de alguma forma com o ensino online no futuro. 
JingxinXu - Sou pessimista no ensino remoto por causa das dificuldades na observação e avaliação de performance de alunos. No que diz respeito aos efeitos da pandemia na educação, atualmente a situação está melhorando aos poucos, mas no meu ponto de vista apenas posso falar sobre a influência para aqueles professores que fazem pesquisa, para eles ficar em casa não é necessariamente algo ruim, mas para outros professores, é preciso gastar mais tempo sem ter a garantia de ter um bom resultado. A partir desse ponto de vista, sou pessimista no ensino remoto por causa das dificuldades na observação e avaliação da performance dos alunos.

Lavota Carter - Eu acho que o covid19 abrirá oportunidades para o aprendizado online ser mais aceito. Os novos recursos advindos irão possibilitar o seu desenvolvimento e implementação em um número crescente de instituições. As áreas de artes e humanidades necessitarão ser reconfiguradas para adaptar a esse modelo de distanciamento e isolamento por um longo período de tempo.

Recebido em 19 de outubro de 2020

Aceito em 09 de novembro de 2020 